\title{
Editor Note: Journal of Allergy and Therapy
}

\section{Cristoforo Incorvaia*}

Allergy/Pulmonary Rehabilitation, ASST Gaetano Pini/CTO, Milan, Italy

*Corresponding author: Cristoforo Incorvaia, Allergy/Pulmonary Rehabilitation, ASST Gaetano Pini/CTO, Milan, Italy, Tel: +390257993289; E-mail: cristoforo.incorvaia@gmail.com

Received date: September 26, 2016; Accepted date: September 29, 2016; Published date: October 03, 2016

Copyright: ( 2016 Incorvaia C. This is an open-access article distributed under the terms of the Creative Commons Attribution License, which permits unrestricted use, distribution, and reproduction in any medium, provided the original author and source are credited

\section{Basal Serum Cortisol and Adrenocorticotropic Hormone Levels in Patients with Atopic Dermatitis}

Atopic dermatitis (AD) is a kind of chronic eczematous skin disease. This skin disease may be genetically inherited. AD is characterized by severe pruritus, xerosis and eczematous lesions. It is also characterized by dry, scaly patches, with intense scratching which further causes skin thicken and darken and may lead to bacterial infections. Skins which are extremely dry can even break down and ooze. Topical steroids are the mainstay of the treatment [1].

Tehranchinia et al. studied the "Basal Serum Cortisol and Adrenocorticotropic Hormone and IgE levels in Patients with AD". In the study the researchers evaluated 31 patients with a mean age of 34.1 \pm 19.2 years with a history of $\mathrm{AD}$ and 31 control subjects matched in age and sex with no history of any inflammatory skin disease or allergies. Enzyme Linked Immunosorbent Assay (ELISA) technique was used to measure morning basal serum cortisol level, serum ACTH level, and serum IgE level in study group as well as in control group. Severity of the disease was evaluated by the Scoring Atopic Dermatits (SCORAD) index.

The researchers reported no statistical difference in the mean basal serum cortisol level as well as ACTH level in the study and control groups. The mean of basal serum cortisol level was $10.09 \pm 5.24 \mathrm{mg} / \mathrm{dl}$ (range 5.1-29.4) in AD group and $9.32 \pm 3.59 \mathrm{mg} / \mathrm{dl}$ (range 5-17.5) in control group, the mean of ACTH level in AD group was $26.76 \pm 17.57$ $\mathrm{pg} / \mathrm{ml}$ (range 6.8-66.8) while it was $26.42 \pm 14.92$ in control subjects. However, the serum IgE level was significantly varying in the two groups. The case group was reported with $328.48 \pm 362.77 \mathrm{Iu} / \mathrm{ml}$ (range 8-1033) while the control group was reported with $121.55 \pm 185.47$ (range 5-932) Serum IgE level. SCORAD index graded $61.28 \%$ of the patients with moderate AD. Serum IgE level was found to be significantly higher in $\mathrm{AD}$ patients and was correlated with disease severity. The results of the study were in accordance to some of the previous studies on the percutaneous systemic absorption of topical steroids leading to suppression of hypothalamic pituitary adrenal axis (HPAA).

\section{Peanut Component Analysis in Monozygotic Twins with Anaphylaxis to Peanut}

Monozygotic twins are the result from same zygote, which at an early stage of development separates into independently growing cell aggregations giving rise to two individuals with similar genetic constitution. Since monozygotic twins have similar genetic constitution, it is believed that the twins will respond similarly to a particular allergen [2].

Robertson et al. reported a case report on the "Peanut Component Analysis in Monozygotic Twins with Anaphylaxis to Peanut". The patients were 2 year old Caucasian monozygotic male twins without any prior diagnosis with any medical problem. Both parents had a history of allergic rhinitis triggered by cat epithelium. Mother had a mild intermittent asthma for which she used inhaled drugs. None of the parents had a history of any food allergy. The two twins were referred to as twin A and twin B. Both the twins were fed with peanut butter for the first time. After 10 minutes of administration twin $\mathrm{A}$ developed itching and hives, and lips swelling developed afterwards. No cough or shortness of breath was reported. In the ED, twin A's symptoms were immediately treated with intramuscular epinephrine, intravenous steroids and an H1-receptor antagonist. Twin A's lab work in the ED revealed a peanut IgE level of $2.1 \mathrm{kUA} / \mathrm{L}$. Twin A was later seen in an outpatient clinic for follow up where additional lab work revealed a peanut IgE level of $2.27 \mathrm{kUA} / \mathrm{L}$, Ara h 2 level of $0.25 \mathrm{kUA} / \mathrm{L}$ and Ara h 1, 3, 8, 9 levels all $<0.1 \mathrm{kUA} / \mathrm{L}$.

Twin B developed itching, hives, flushing, lacrimation, cough, face/lip/tongue swelling and tachycardia within 10 minutes of consuming the same quantity of peanut butter as twin $\mathrm{A}$. In the ED, twin B's symptoms were treated identically to twin A. Twin B's lab work in the ED revealed peanut IgE level of $26.2 \mathrm{kUA} / \mathrm{L}$. Twin B also had additional lab work done later in the outpatient setting which revealed peanut IgE level of $7.30 \mathrm{kUA} / \mathrm{L}$, Ara h 2 level of $1.49 \mathrm{kUA} / \mathrm{L}$, Ara h 9 level of $0.64 \mathrm{kUA} / \mathrm{L}$ and Ara h 1, 3, 8 levels all $<0.1 \mathrm{kUA} / \mathrm{L}$.

The case report revealed that in spite of having same genetic makeup, monozygotic twins may respond differently to a same allergen source from clinical and antigen processing perspective. In fact, one twin reacted only cutaneously while the other identical twin showed anaphylaxis with cough, tachycardia, tearing and additional skin manifestations on exposure to same allergen.

\section{Predictors of Pregnancy Outcome in Antiphospholipid Syndrome: A Review}

Antiphospholipid syndrome (APS), also known as Hughes syndrome, is an autoimmune disorder which causes venous or arterial thrombosis or miscarriage. APS is characterised by high levels of antibodies directed against membrane anionic phospholipids or their associated plasma proteins or evidence of circulating anticoagulant [3].

Tabacco et al. reviewed the different predictors of poor pregnancy outcome in women with APS. Different researchers had suggested that intra-placental thrombosis is the main pathogenic event associated with maternal and foetal complications of APS pregnancies, whereas other studies demonstrate anti-phospholipid antibodies to be playing an interfering role. Based on the different researches, the author concluded that Doppler velocimetry in the second trimester is a useful tool for identifying APS resulting in poor pregnancy outcome. It was also suggested that the presence of CMV IgM false positivity could present a novel prognostic factor in poor outcomes in APS 
pregnancies. By reviewing different data, the authors concluded triple aPL positivity as a good diagnostic tool for the same. Other data provided by author suggest hypocomplementemia could be considered as a prognostic factor for pregnancy outcomes in APS. Identifying different variables associated with pregnancy failure can come up with positive result in APS pregnancies.

\section{References}

1. Tehranchinia Z, Rahimi H, Lotfi S (2016) Basal Serum Cortisol and Adrenocorticotropic Hormone Levels in Patients with Atopic Dermatitis. J Allergy Ther 7:236.
2. Robertson LM, Frith JA, Tcheurekdjian H, Hostoffer RW (2016) Peanut Component Analysis in Monozygotic Twins with Anaphylaxis to Peanut. J Allergy Ther 7:234.

3. Sara T, Silvia S, Sara DC, Angela B, Sergio F, et al. (2016) Predictors of Pregnancy Outcome in Antiphospholipid Syndrome: A Review. J Allergy Ther 7:235. 